\title{
"ARTESANATOS" MIDIÁTICOS: ESTUDO DE ARTES VISUAIS DIFUSAS EM TV E REDES MIDIÁTICAS
}

\section{MIDIATIC "CRAFTS”: STUDY OF THE VISUAL ARTS DIFFUSES IN TV AND MIDIATIC NETWORKS}

\author{
DOI: http://dx.doi.org/10.5965/1984317815032019056 \\ Aparecida Santos Scarpioni \\ Câmara Municipal de Rio Grande da Serra/SP \\ scarpionisantos@gmail.com \\ Marcos Scarpioni \\ Universidade Metodista de São Paulo \\ scarpionim@gmail.com
}

\begin{abstract}
RESUMO
O conceito de arte visual é muito amplo, o qual envolve diversas linguagens como: pintura, fotografia, cinema, escultura, etc. Entre as múltiplas formas e frentes das artes visuais estaria o artesanato, vigorando em meio às artes manuais e das artes populares. Neste trabalho buscamos analisar a abordagem implícita das artes visuais e suas metodologias de ensino utilizadas na confecção de objetos decorativos e/ou utensílios domiciliares que são apresentados em programas televisivos e redes midiáticas. A fim de compreender quais são as motivações e influências das artes visuais no cotidiano dos telespectadores é que questionamos: Existiria ênfase de fato nas artes visuais nos ditos "artesanatos midiáticos"? Objetiva-se então compreender em que medida a arte visual pode estar implícita na confecção de objetos e serviços, contribuindo na melhoria da qualidade de vida daqueles que desenvolvem tais práticas "artesanais". Como procedimentos metodológicos, utilizamos a observação empírica em campo, a identificação e o registro de conteúdos de programas televisivos e em redes midiáticas, e então, efetivamos a discussão de seus conteúdos como será provado ao final.
\end{abstract}

Palavras-chave: Artes Visuais. Metodologias de Arte. Artesanatos. Ensino.

\begin{abstract}
The concept of the visual art is very ample, that which envolve several languages with: painting, fotograph, sculpture, between others. Among the form multiples and frent of the visual arts will be the craft strengthing in middle the manual arts and popular arts. In this work seeking analyse the implicit approaches the visual arts and theirs methodology of the instruction employed in the making of the decorative objects and/or utensils domestic which will be showed in television programs and the midiatic networks. For of the comprehend which be the motivations and influences of the visual arts in the quotidian of the telespectators will which asking: There is emphasis of the fact $n$ the visual arts through of the sames "midiatic crafts"? Thus objective then comprehend in which degree the visual arts allow be implicit in the making of the objects and services, coming give in the improvement of the quality of the live of that which desenvolving such practices "crafts". Using how methodological proceeding, the empiric observation in field, register contents of the television programs and midiatic networks, and then executing the discussion of the theirs contents wich will be proved in the finish.
\end{abstract}

Keywords: Visual Arts. Methodology of the Art. Crafts. Teaching. 


\section{INTRODUÇÃO}

O uso das tecnologias facilita o acesso aos meios de informação e comunicação. Nesse contexto, se inserem e são difusas as feiras de artesanatos grande parte das cidades brasileiras - principalmente nas turísticas, contribuindo para o consumo de arte. Para Santaella (2016), "as artes contemporâneas tornaram-se indispensáveis na sociedade pós-moderna", por serem "modos específicos de manifestação da atividade criativa dos seres humanos ao interagirem com o mundo em que vivem, ao se conhecerem e ao conhecêIo" (FERRAZ; FUSARI, 1993, p.16).

Machado (2008, p. 5) afirma que a "arte sempre foi produzida com os meios do seu tempo" daí, quiçá a explicação da inserção daquilo que se conhece popularmente como arte difusa na mídia em nossos dias. Talvez, as artes deste novo século XXI, englobam o conceito de "arte visual", o qual em um continuum já estaria intrínseco ao das artes modernas conforme Walter Benjamin afirmou, pois estas já eram "passíveis de reprodutibilidade". Entretanto, assim como conceituar, interpretar aquilo que é a arte contemporânea é algo deveras complexo e que dá margem, a "um emaranhado de interpretações desencontradas" (SANTAELLA, 2016, p. 128), o conceito de artes visuais também é muito amplo composto por muitas áreas, técnicas, linguagens, como: dança, teatro, cinema, fotografia, pinturas, colagens, moda, gravuras, esculturas, arquitetura, paisagismo, decoração etc., conforme conceituam (BUENO, 2012; ZAGONEL, 2012; BRASIL, 1997; FERRAZ \& FUSARI, 1993).

Em virtude disso, este trabalho tem como principal foco a identificação das artes visuais e de sua metodologia de ensino nas ditas "atividades artesanais" difundidas em programas televisivos ${ }^{1}$, canais religiosos ${ }^{2}$ e também nas

1 São todos conteúdos de entretenimento e de informações ao público, disponíveis pelas TV aberta e TV a Cabo.

2 Que estão presentes nas TV a Cabo, como: Rede Aparecida, Rede Novo Tempo, Rede Canção Nova, entre outras. 
redes $^{3}$ midiáticas, ou seja, a arte que desperta olhares, encanta por suas formas e traços.

Nosso tema abordado são artes visuais presentes nos "artesanatos" que são ensinados através dos meios de comunicação de massa, logo plasmando a arte na mídia, ou seja, "a arte se apropriando da tecnologia" (MACHADO, 2008, p.15) e vice- versa, na medida em que surgem produções artísticas por meio da tecnologia.

O objeto de pesquisa encerrado neste ensaio pode ser descrito como a inserção das artes visuais e suas metodologias na produção de objetos e serviços laborais com características "artesanais", práticas difundidas em programas televisivos e/ou nas redes midiáticas, e consecutivamente, suas influências no público alvo. Por isso, identificamos inicialmente uma gama de programas televisivos em canais religiosos e outros, os quais difundem, categoricamente, trabalhar e/ou ensinar algum tipo de arte visual imbricada nos ditos "artesanatos".

Dessa maneira, percebemos que podem ser ou "são inúmeras as maneiras dos artistas [...] [manifestarem-se] visualmente, e com a tecnologia em contínua evolução, temos formas de expressão bem diversificadas, aumentando ainda mais a riqueza artística" (BUENO, 2012, p. 124). Logo, o artesanato é uma das mais ricas formas de expressão cultural de um povo, sendo a representação histórica de comunidades, bem como a transmissão de um legado às futuras gerações (SEBRAE, 2014, p. 01), por conseguinte é uma expressão de um tipo bem específico de Arte, um segmento da Arte ou a própria Arte. Para Zagonel (2012, p. 31) essas "diversas produções artísticas são geradoras de negócios e de riquezas e, consequentemente, de empregos, conforme revela estudos sobre a cadeia produtiva em diversos setores de produção artística". Assim, o artesanato tem impactos na inclusão social e no desenvolvimento local, regional, nacional (SEBRAE, 2014).

3 São as redes que estão construídas a partir do relacionamento sincrônico e assincrônico de pessoal no espaço virtual. Como exemplo de redes midiáticas abordadas neste ensaio, citamos: Facebook, Youtube, Badoo, Canais de TVs na Internet, Canais temáticos, entre outros. 
Dessa maneira, justificamos nosso interesse em estudar as artes visuais e suas metodologias de arte imbricadas nos ditos artesanatos para a compreensão de sua difusão na sociedade, afinal, se faz interessante na medida em que nos permite compreender como as pessoas aprendem, fixam um conhecimento artístico desenvolvendo habilidades e competências para a tomada de decisão e de seu protagonismo profissional em sociedade e nos diversos espaços de socialização. Outra motivação para estudar o referido objeto seria a escassez de bibliografias que tratam deste assunto, especificamente o tipo de análise aqui proposta. Embora, exista uma vasta e acurada bibliografia tratando de conceitos de arte e suas bases teóricas elaboradas por Lúcia Santaella e das interações da arte com a mídia apresentadas por Anna Barros, Arlindo Machado, Jorge Coli, entre outros, no que tange a distinção dos conceitos artesanatos, manualidades e artes populares - conceitos que não estão explícitos ou são abordados superficialmente nos programas televisivos e nas redes midiáticas não encontramos.

Por isto, acreditamos que a divulgação e/ou exposição daquilo que está compreendido como - as artes visuais nos meios de comunicação de massa se constituem em um fato relevante a ser pesquisado de maneira constante, principalmente no que tange a "metamorfose e o mimetismo da arte" (MACHADO, 2008). Consequentemente, investigar os programas televisivos e canais que abordam algum de trabalho dito "artesanal" permite-nos entender quais podem ser as motivações, intenções, interesses daqueles que os produzem ou patrocinam tais programas, a saber: a difusão de costumes, cultura das artes, o incentivo ao consumo de bens e serviços, o ensino das artes sacras, etc.

Nossa pesquisa por ser uma pesquisa exploratória de campo, servimonos da técnica de pesquisa - observação empírica. Seguimos observando e registrando os programas televisivos, e ainda, aqueles disponíveis em redes midiáticas, os quais apresentam "artesanatos" nos quais presumidamente e inicialmente estariam implícitas as artes visuais e questionamos: a) Os conteúdos apresentados em programas televisivos e nas redes midiáticas que abordam o tema artesanatos estariam de fato ensinando artesanato e as artes visuais? b) 
As artes visuais estariam inseridas nesses artesanatos, nos trabalhos manuais e nas artes populares como se comenta nesses programas ou elas inexistem nessas práticas? c) A demonstração de como confeccionar objetos e demais produtos ditos "artesanais", seria uma metodologia de arte eficaz para o ensino e a aprendizagem de artes visuais para aqueles que assistem a esses programas? d) As atividades laborais exibidas nos programas, ao incentivarem o comércio e consumo de produtos industrializados para a feitura de objetos domiciliares estariam contribuindo para a descaracterização da arte visual que porventura esteja implícita no artesanato? e) O artesanato possui uma metodologia de arte própria que a diferiria da metodologia de ensino de artes difusas em revistas, livros, CD-ROMs, DVDs ofertados nesses programas, e ainda, seria esta diferente da metodologia de ensino de artes visuais nas escolas?

Como objetivo geral, buscamos compreender como as artes visuais e suas metodologias podem (ou não) estar inseridas nos conteúdos dos "programas de artesanatos" presentes na mídia em geral. Neste sentido, por objetivos específicos abarcamos: 1) discutir como as artes visuais estariam ou não, presentes no artesanato, nos trabalhos manuais e nas artes populares que podem ser abordadas nesses programas;

2) Compreender as potencialidades de como a demonstração e elaboração de objetos e demais produtos ditos "artesanais" pode ser eficiente, eficaz para o ensino-aprendizagem das artes visuais para os telespectadores e seguidores desses programas; 3) Debater sobre e como, esses programas criam, despertam interesse e quiçá a compreensão das artes visuais em sentido mais amplo. Assim, ao longo deste trabalho, empreendemos esforços para encontrar as respostas pertinentes ao objeto de nossa pesquisa e assim compreender melhor as artes visuais e as suas metodologias de ensino, e assim efetivamos as seguintes etapas:

a) Levantamento bibliográfico sobre o tema a ser trabalhado na pesquisa em diversas fontes bibliográficas, como: livros, artigos científicos, internet, ba- 
ses de dados, etc. tendo como principais fontes de dados Periódicos da Capes e Scielo.

b) Observação empírica dos programas televisivos em canais de TV aberta e TV a Cabo que abordavam a temática do trabalho em diversos horários (manhã, tarde e a noite) realizado na própria residência da autora desta pesquisa. Com o auxílio de um tablet ${ }^{4}$, efetivamos a gravação de programas em vários horários (manhã e tarde). As gravações foram feitas da seguinte maneira: paramos em frente ao televisor para gravar os programas, seus apresentadores, convidados, as técnicas "artesanais", enfim, a dinâmica de cada programa.

c) Visitas, observações e gravações de programas disponíveis nas redes sociais, como: Canais de TVs, Canais Temáticos, Youtube, Facebook que difundem os ditos "artesanatos" na internet, etc. em um banco de dados. Ressaltamos que as visualizações e gravações foram realizadas no período de 03/08 à 31/10/2016, totalizando 90 dias.

\section{AS ARTES, ARTES VISUAIS E OS ARTESANATOS}

\subsection{Breve definição de Arte e seu Ensino na Pós-Modernidade}

Conceituar o que é Arte é no mínimo uma tarefa difícil, árdua (COLI, 1995), ainda mais se quisermos evitar simplificações ou reducionismos.

Afinal, tratar o termo de maneira simplista é retirar do mesmo, uma intrincada rede de relações humanas que influenciam a vida cotidiana, a(s) realidade(s) e o pensamento imaginário e reflexivo que cada ser humano pode ma-

\footnotetext{
${ }^{4}$ Samsung Galaxy Tab 3 Lite SM-T110. Conforme Condo, Martins \& Scarpioni (1998, p. 648) os recursos audiovisuais se prestam a instrumentalização daqueles que aprendem ou daqueles que ensinam, haja vista, a expansão dos vários recursos disponíveis em nossa sociedade pósmoderna inserido nos diversos ambientes de ensino-aprendizagem.
} 
terializar em sociedade, especialmente na sociedade pós-moderna ${ }^{5}$ e pós-industrial conforme expõe Lúcia Santaella (2016) em um de seus artigos ${ }^{6}$.

Engelmann (2012, p. 52) afirma que arte etimologicamente deriva do latim ars que significa: meio adequado para a obtenção de determinado resultado, assim como do grego tékne, termo que possui a mesma conotação. Barros (2002, p. 34) assegura que a "arte apareceu com o homo sapiens, quando o cérebro alcançou suas dimensões plenas". Garcia Júnior (2014) corrobora com este pensamento ao definir a Arte como:

[...] uma das primeiras manifestações da humanidade como forma do ser humano marcar sua presença criando objetos e formas (pintura nas cavernas, templos religiosos, roupas, quadros, filmes etc.) que representam sua vivência no mundo, comunicando e expressando suas ideias, sentimentos e sensações para os outros (GARCIA JÚNIOR, 2014, p.04).

Engelmann afirma ter sido na Grécia Antiga, o epicentro da filosofia das artes perpassando por períodos e estilos ao longo dos muitos séculos até nossos dias. Entretanto, cabe dizer que já existiam outras formas, pensamentos e expressões artísticas para além do continente europeu e desse período especificamente como demonstra Garcia Júnior, pois para o autor, é preciso pensar em outras formas de artes que estão espalhadas pelos diversos continentes, que seriam: "Arte Mesopotâmica, Arte Egípcia, Arte Pré-Colombiana nas Américas, Arte Africana" (GARCIA JÚNIOR, 2014, p. 56), entre tantas outras.

Mas seria no renascentismo e modernidade que filósofos alemães como Kant, Hegel, Heidegger trariam um conjunto de pistas em direção às definições sobre Arte. Engelmann (2012, p. 38). O autor remetendo-se a Kant declara que a arte está intrinsecamente ligada à ética e a moral. E mais, esta arte seria a "portadora de uma cultura aceita por todos e baseada em costumes sumaria-

\footnotetext{
${ }^{5}$ A citarmos a Sociedade Pós-Moderna, estamos referenciando um novo comportamento social induzido, motivado a partir das novas tecnologias de comunicação, de produção de bens e serviços, de novas interações econômicas globais as quais aceleram informações nos veículos de comunicação logo após as primeiras décadas do pós-guerra.

6 Sob o título: "A arte contemporânea e seus enigmas" apresentado no $15^{\circ}$ Encontro Internacional de Arte e Tecnologia, realizado em Brasília.
} 
mente estabelecidos e delineados [...] a fim de manter a dignidade humana" (ENGELMANN, 2012, p. 39).

Em Hegel, como referencia Engelmann (2012, p.41-42), a arte é uma manifestação particular do espírito, a qual juntamente com a filosofia e religião seria o domínio absoluto do espírito humano, afinal, somente o humano pode criar e recriar e [ainda] atribuir significações [as coisas e fatos]. Também Engelmann (2012, p.47), afirma que Heidegger definia a arte pela história, e também, por uma identidade de uma sociedade, consistindo na instauração de vontade e também, a forma pela qual o povo se insere na história.

Portanto, para Engelmann (2012) a arte tem um foco de convergência de valores religiosos, sociais, políticos, éticos, morais e estéticos. Dessa forma, estaria posto que ao intentarmos conceituar o que seja arte, penetramos em um universo de inúmeras definições, classificações, períodos históricos, estilos, por exemplo: artes plásticas, artes sacras, artes visuais entre outras.

Mas, é diante dessa multiplicidade de definições, entendimentos e interpretações é que surgiram e perduram questionamentos e/ou dúvidas como a de Mário de Andrade até os dias atuais, seria mesmo possível ensinar artes? E aqui complementamos esta, e arte a partir do artesanato?

Para Andrade o ensino das artes mereceu críticas em sua década. Segundo Andrade (1938, p. 02), a "arte na realidade não se aprende. Mas a arte se confunde com o artesanato por motivo de algumas semelhanças que 0 artista tem de ser ao mesmo tempo artesão". De acordo com o autor, o artesanato seria uma parte da técnica da arte, [...] assim a técnica da arte não se resume no artesanato. Mas o artesanato é uma parte da técnica que pode se ensinar. Contrapondo a esse questionamento e crítica, encontramos em Walter Benjamin respostas que demonstram a reprodutibilidade técnica de obras de arte, ou melhor, das artes em sentido amplo como o autor expõe no discorrer do seu escrito. Para Benjamin (1987):

Em essência, a obra de arte sempre foi reprodutível. O que os homens faziam sempre podia ser imitado por outros homens. 
Essa imitação era praticada por discípulos, em seus exercícios, pelos mestres, para a difusão das obras, e finalmente por terceiros, meramente interessados no lucro. Em contraste, a reprodução técnica da obra de arte representa um processo novo, que se vem desenvolvendo na história intermitentemente, através de saltos separados por longos intervalos, mas com intensidade crescente (BENJAMIN, 1987, p.166).

Neste pensamento, observamos a exclusão da criatividade, das emoções do artista impressa em cada obra, seja ela pintura, escultura, xilogravura, etc., mas, a existência de uma técnica sistematizada, absorvida e aplicada em cada novo objeto que vai se reproduzindo.

\subsection{Artes Visuais, Inteligências Múltiplas, Inteligências Emocionais e suas Mútuas Relações}

As artes como já foi abordado anteriormente, seriam a resultante da materialização do imaginário e da expressão de sentimentos que um artista fixa na confecção de objetos, de obras artísticas, e ainda, pelos inúmeros entendimentos imprimidos por parte daqueles que as visualizam. Nessa relação de fazer e contemplar um objeto, uma obra é que emergem as artes visuais. Logo arte e inteligência emocional guardam relações diretas entre si.

Na década de 80, conforme Amaral (2007, p. 06) diz, Howard Gardner afirmava que inteligência estava definida como "a habilidade para resolver problemas ou criar produtos que sejam significativos em um ou mais ambientes culturais". Portanto, para Gardner todos nós temos não uma inteligência, mas, inteligências múltiplas (AMARAL, 2007; GOLEMAN, 2011; LAKOMY, 2012). Assim, "inicialmente [Gardner] propôs sete tipos de inteligência, porém, é possível que existam outras" (SMOLE, 1999, p. 09). Sendo elas: linguística, lógicomatemática, musical, espacial, corporal-cinestésica, interpessoal, [intrapessoal] (SMOLE, 1999; AMARAL, 2007). Lakomy (2012) descreve ainda, a existência da inteligência naturalista, incrementando a lista, só para termos conhecimento. 
Quadro 1. As classificações das Inteligências e as habilidades propostas por Gardner

\begin{tabular}{|c|c|}
\hline $\begin{array}{c}\text { TIPOS DE } \\
\text { INTELIGÊNCIA }\end{array}$ & CARACTERÍSTICAS/HABILIDADES \\
\hline LINGUÍSTICA & $\begin{array}{l}\text { se manifesta na habilidade para lidar criativamente com as palavras, em diferentes } \\
\text { Níveis de linguagem (semântica, sintaxe), tanto na expressão oral quanto na } \\
\text { escrita (no caso de sociedades letradas) }\end{array}$ \\
\hline $\begin{array}{l}\text { LÓGICO- } \\
\text { MATEMÁTICA }\end{array}$ & $\begin{array}{l}\text { é característica de pessoas que são boas em lógica, matemática e ciências. É a } \\
\text { inteligência que determina a habilidade para o raciocínio lógico-dedutivo e para a } \\
\text { compreensão de cadeias de raciocínios, bem como a capacidade de solucionar } \\
\text { problemas envolvendo números e elementos matemáticos. }\end{array}$ \\
\hline MUSICAL & $\begin{array}{l}\text { a capacidade de pensar em termos musicais, reconhecer temas melódicos, ver } \\
\text { como eles são transformados, seguir esse tema no decorrer de um trabalho } \\
\text { musical e, mais ainda, produzir música. É a inteligência que permite a alguém } \\
\text { organizar sons de maneira criativa, a partir da discriminação de elementos como } \\
\text { tons, timbres e temas }\end{array}$ \\
\hline ESPACIAL & $\begin{array}{l}\text { corresponde à habilidade de relacionar padrões, perceber similaridades nas } \\
\text { formas espaciais e conceituar relações entre elas. Inclui também a capacidade de } \\
\text { visualização no espaço tridimensional e a construção de modelos que auxiliam na } \\
\text { orientação espacial ou na transformação de um espaço. }\end{array}$ \\
\hline $\begin{array}{l}\text { CORPORAL- } \\
\text { CINESTÉSICA }\end{array}$ & $\begin{array}{l}\text { é uma das competências que as pessoas acham mais difícil aceitar como } \\
\text { inteligência. Cinestesia é o sentido pelo qual percebemos nosso corpo - } \\
\text { movimentos musculares, peso e posição dos membros etc. Então, a inteligência } \\
\text { cinestésica se refere à habilidade de usar o corpo todo, ou partes dele, para } \\
\text { resolver problemas ou moldar produtos. }\end{array}$ \\
\hline INTERPESSOAL & $\begin{array}{l}\text { a habilidade de compreender as outras pessoas: como trabalham, o que as } \\
\text { motiva, como se relacionar eficientemente com elas. Esse tipo de inteligência é a } \\
\text { que sobressai nos indivíduos que têm facilidade para o relacionamento com os } \\
\text { outros inclui a habilidade de compreender as outras pessoas: como trabalham, o } \\
\text { que as motiva, como se relacionar eficientemente com elas. Esse tipo de } \\
\text { inteligência é a que sobressai nos indivíduos que têm facilidade para o } \\
\text { relacionamento com os outros. }\end{array}$ \\
\hline INTRAPESSOAL & $\begin{array}{l}\text { é a competência de uma pessoa para se autoconhecer e estar bem consigo } \\
\text { mesma, administrando seus sentimentos e emoções a favor de seus projetos. } \\
\text { Significa dimensionar as próprias qualidades de trabalho de maneira efetiva e } \\
\text { eficaz, a partir de um conhecimento apurado de si próprio, ou seja: reconhecer os } \\
\text { próprios limites, aspirações e medos e utilizar esse conhecimento para ser } \\
\text { eficiente no mundo. }\end{array}$ \\
\hline
\end{tabular}

Fonte: Adaptado de Múltiplas Inteligências na Prática Escolar (SMOLE, 1999, p. 11-13).

Mas para Goleman (2011, p.18) existiria ainda um outro tipo de inteligência diferente da proposta por Gardner, e que englobaria as inteligências múltiplas. Este tipo de inteligência não considera não só as razões, mas também as emoções que cada indivíduo tem e como lida com estas, uma inteligência que possui "aspectos fundamentais, como: autoconsciência, autocontrole, consciência social e a habilidade de gerenciar relacionamentos", aspectos que também influenciam as artes. Logo podemos observar que a prática da 
confecção de produtos artesanais ou das artes visuais só é possível em virtude de uma inteligência (artística) ou de um conjunto de inteligências combinadas (lógico-matemática, espacial, corporal-cinestésica, entre outras) das quais os artesões e artistas extraem de suas inspirações e as materializam-nas na forma de objetos e demais trabalhos artísticos. Nota-se então que estas inteligências vão sendo cada vez mais desenvolvidas nesse contexto de laissez-faire e pela retroalimentação do fazer das artes e sobre estas, à reflexão no contemporâneo.

Assim, as artes visuais abrem uma gama de possibilidades de ensino em suas várias formas por meio das diversas metodologias e técnicas que vão sendo construídas, adaptadas ou conjugadas, para se atingir os objetivos propostos em cada segmento artístico, dentro ou fora de estabelecimentos de ensino.

\subsection{Artesanatos, Artes Manuais e Artes Populares - A arte do fazer e a li- nha tênue na produção de bens e serviços na sociedade pós-moderna}

Para analisarmos os conteúdos dos programas televisivos e os de redes midiáticas, faz-se necessário um marco conceitual.

Por isso, o delinear e distinguir os conceitos sobre artesanato, artes manuais ${ }^{7}$ e as artes populares, etc., bem como, com o auxílio da teoria das inteligências múltiplas, refletir sobre conteúdos dos programas aqui propostos. Segundo Lima (2011, p.01) "existem palavras muito perigosas porque, quando empregadas, podem encobrir a realidade ao invés de desvelá-la [...]. Este é o caso dos termos artesanato, [trabalhos manuais] e arte popular" (LIMA, 2011, p.01). Por isso, há a necessidade de se compreender os termos bem definidos e usá-los adequadamente, evitando seu uso de maneira indiscriminada como se tudo significasse uma coisa só, pois não faz sentido desvalorizar um em detrimento do outro, ou dar valor igual, nivelando por baixo coisas totalmente distintas com significados diversos. Por isso, buscamos fazer nossa análise por

\footnotetext{
7 (também conhecida como trabalhos manuais ou manualidades)
} 
meio das leis e das interpretações conceituais de teóricos que tratam do assunto, bem como seus empregos no contexto sociocultural e produtivo.

No art. $1^{\circ}$ da lei n. $13.180 / 2015$, observamos a definição para artesão sendo: "toda pessoa física que desempenha suas atividades profissionais de forma individual, associada ou cooperativada" (BRASIL, 2015). Mas o art. $2^{\circ}$ da portaria n. 29/2010 Ministério do Desenvolvimento, Indústria e Comércio Exterior (MDIC) o artesão é o trabalhador que de forma:

individual exerce um ofício manual, transformando a matériaprima bruta ou manufaturada em produto acabado. Tem o domínio técnico sobre materiais, ferramentas e processos de produção artesanal na sua especialidade, criando ou produzindo trabalhos que tenham dimensão cultural, utilizando técnica predominantemente manual, podendo contar com o auxílio de equipamentos, desde que não sejam automáticos ou duplicadores de peças (MDIC, 2010, p.01).

De acordo com o estabelecido pelo Conselho Mundial de Artesanato (WCC) 8 e como referencia Barroso Neto ( 2001 , p.3). - Artesanato é toda "atividade produtiva de objetos e artefatos realizados manualmente, ou com a utilização de meios tradicionais ou rudimentares, com habilidade, destreza, apuro técnico, [...]". Esta definição proposta pelo WCC foi também recepcionada pelo Serviço de Apoio a Micro e Pequena Empresa (SEBRAE, 2010, p. 12).

Para a Superintendência ${ }^{9}$ do Trabalho Artesanal nas Comunidades (Sutaco) o artesanato pode ser definido como "sendo um trabalho predominantemente manual ( $80 \%$ ou mais) que pode ser feito com o auxílio de instrumentos manuais ou máquinas simples" (SUTACO, 2016, p.01). Nota-se que essa última definição dá margens para interpretações confusas que se misturam com

\footnotetext{
8 World Craft Council (Conselho Mundial de Artesanato).

9 Inicialmente essa instituição foi uma autarquia pública criada pelo Decreto-Lei $n^{\circ} 256$, de 29 de maio de 1970 a qual estava atrelada a Secretaria de Emprego e Relações do Trabalho, tendo como a finalidade de desenvolver e preservar o rico artesanato paulista como é possível consultar no Wikipédia. Atualmente após um processo de reformulação a instituição passou a ser a Subsecretaria do Trabalho Artesanal nas Comunidades - SUTACO é vinculada à Secretaria de Desenvolvimento Econômico, Ciência, Tecnologia e Inovação (SDECTI) http://acervo.sutaco.sp.gov.br/. Cabe ressaltar que o site foi todo reformulado também e as informações anteriores foram retiradas do sítio.
} 
as atividades manuais como discorreremos a frente. Aliás, talvez aí esteja o motivo desta superintendência promover reformulações nas informações do sítio $^{10}$ e da consulta pública sobre a base conceitual do artesanato paulista.

Pela portaria n. 29/2010 (MDIC), estão definidos o que são: artesanato, arte popular e trabalho manual, além de mostrar os delineamentos conceituais envolvidos em cada um dos termos. Portanto, para MDIC (2010) no art. $4^{\circ}$ da referida portaria o artesanato:

[...] compreende toda a produção resultante da transformação de matérias-primas, com predominância manual, por indivíduo que detenha o domínio integral de uma ou mais técnicas, aliando criatividade, habilidade e valor cultural (possui valor simbólico e identidade cultural), podendo no processo de sua atividade ocorrer o auxílio limitado de máquinas, ferramentas, artefatos e utensílios (MDIC, 2010, p. 03, grifo nosso).

Além de definir o que é artesanato, a portaria define também aquilo que não é artesanato em seu artigo $4^{\circ} \S 1^{\circ}$ :

I - Trabalho realizado a partir de simples montagem, com peças industrializadas e/ou produzidas por outras pessoas; II - Lapidação de pedras preciosas; III - Fabricação de sabonetes, perfumarias e sais de banho, com exceção daqueles produzidos com essências extraídas de folhas, flores, raízes, frutos e flora nacional; IV - Habilidades aprendidas através de revistas, livros, programas de TV, dentre outros, sem identidade cultural (MDIC, 2010, p.03, grifo nosso).

Entretanto, Lima (2011) ressalta que o artesanato seria uma maneira de fazer objetos que existe há milênios.

O termo artesanato deve ser mais empregado ao nos referirmos ao período pós Revolução Industrial (LIMA, 2011, p. 02). Porém, quando o objeto criado pela indústria passou a ser oposição ao hand made, o "fazer com as próprias mãos" este termo ganhou novas conotações e abordagens.

10 Conforme foi possível consultar no sítio: www.sutaco.sp.gov.br 
No caso das manualidades, Barroso Neto (2001, p.04) afirma que o WCC tem a seguinte definição para tal prática: é "uma atividade manual é em geral uma ocupação secundária, utilizando-se o tempo disponível ou ocioso com o objetivo principal de complementar a renda familiar". Para o autor, o tempo e a paciência são fatores essenciais que agregam valores na confecção de um produto advindo de uma atividade manual, todavia, dispensa o valor cultural que se faz necessário no artesanato. E ainda, o autor afirma que este por ser um trabalho essencialmente repetitivo, todavia requerendo destreza e habilidade, os mesmos podem prescindir a capacidade artística e criativa capaz de intervir e alterar cada nova peça executada. Para Sebrae (2010) os trabalhos manuais:

[...] exigem destreza e habilidade, porém utilizam moldes e padrões predefinidos, resultando em produtos de estética pouco elaborada. Não são resultantes de processo criativo efetivo. É muitas vezes, uma ocupação secundária que utiliza o tempo disponível das tarefas domésticas ou um passatempo (SEBRAE, 2010, p. 13, grifo nosso).

Os trabalhos manuais são conceituados pela Sutaco (2016) como sendo:

[...] produto resultante de atividade exclusivamente manual ou apoiada em instrumento ou máquina simplificada. Esse trabalho não tem obrigatoriamente características culturais específicas e não atinge a qualificação de peça única, exclusiva. Sendo cópia ou não, o trabalho manual se caracteriza pela produção limitada, não podendo ser produzido em série. A unidade de produção deve ser o domicílio do produtor ou outro local de convivência, sem o auxílio de terceiros assalariados (SUTACO, 2016, p.01, grifo nosso).

De acordo com o art. $6^{\circ}$ da portaria n. 29/2010 do MDIC, temos que:

TRABALHOS MANUAIS - Apesar de exigir destreza e habilidade, a matéria-prima não passa por transformação. Em geral são utilizados moldes pré-definidos e materiais industrializados. As técnicas são aprendidas em cursos rápidos oferecidos por entidades assistenciais ou fabricantes de linhas, tintas e insumos. $\S 1^{\circ}$ Normalmente é uma ocupação secundária, 
realizada no intervalo das tarefas domésticas ou como passatempo.

[...]. São produtos sem identidade cultural e de baixo valor agregado. $\S 2^{\circ}$ Características dos Trabalhos Manuais: I Segue moldes e padrões pré-definidos difundidos por matrizes comercializadas e publicações dedicadas exclusivamente a trabalhos manuais; II - Apresenta uma produção assistemática e não prescinde de um processo criativo e efetivo; III - Utiliza matérias e técnicas de domínio público; IV Produtos baseados em cópias, sem valor cultural que identifique sua região de origem ou o artesão que o produziu; $V$ - Normalmente utiliza matéria-prima industrializada ou semi-industrializada; IV - Recebe influência global (MDIC, 2010, p. 04, grifo nosso).

Para Barroso Neto (2001, p. 04) nesta categoria de manualidades incluise em geral "as roupas de bebê, toalhas, colchas, almofadas com aplicações de rendas e bordados, crochê, tapetes, cestos, caixas, e uma infinidade de pequenos objetos para o lar ou de uso pessoal como acessórios e bijuterias". Tais objetos de uso doméstico, decorativos, podem sim trazer elementos básicos das artes visuais, entretanto, estes são resultantes de técnicas bem especificas como, por exemplo: pinturas, tecelagens, sem, contudo, ser artesanato.

Neste contexto das definições, temos ainda a arte popular. De acordo com o Sebrae (2010, p. 12) arte popular é "conjunto de atividades poéticas, musicais, plásticas e expressivas que configuram o modo de ser e de viver do povo de um lugar". Embora esta pareça ser uma definição simplista em um primeiro instante, esta é deveras muito abrangente. Barroso Neto (2001) afirma que "conceituar a arte popular não é uma tarefa fácil", mas pode ser compreendida como:

[...] o conjunto de atividades poéticas, musicais, plásticas e expressivas, que configuram o modo de ser e de viver daquela parcela da população de menor grau de instrução formal e distanciada do acesso (tanto física quanto econômica) aos bens e serviços ofertados pela sociedade industrial e urbana. "A arte popular diferencia-se do artesanato a partir do propósito de ambas atividades. Enquanto o artista tem profundo compromisso com a originalidade, para o artesão esta é uma situação meramente eventual (BARROSO NETO, 2001, p. 25). 
De acordo com o art. $5^{\circ}$ da portaria n. 29/2010 MDIC, a arte popular está conceituada da seguinte maneira:

ARTE POPULAR - Conjunto de atividades poéticas, musicais, plásticas, dentre outras expressivas que configuram o modo de ser e de viver do povo de um lugar. A arte popular diferencia-se do artesanato a partir do propósito de ambas as atividades. Enquanto $o$ artista popular tem profundo compromisso com a originalidade, para o artesão essa é uma situação meramente eventual. $O$ artista necessita dominar a matéria-prima como o faz o artesão, mas está livre da ação repetitiva frente a um modelo ou protótipo escolhido, partindo sempre para fazer algo que seja de sua própria criação. Já o artesão quando encontra e elege um modelo que o satisfaz quanto à solução e forma, inicia um processo de reprodução a partir da matriz original, obedecendo a um padrão de trabalho que é a afirmação de sua capacidade de expressão. A obra de arte é peça única que pode, em algumas situações, ser tomada como referência e ser reproduzida como artesanato. $\S 1^{\circ}$ Características do Artista e da Arte Popular:I - Pertence ao povo; II - Revela a identidade cultural regional; III - Personifica a peça; IV - Produz obras assinadas; V - Busca a realidade; VI - Traduz o belo; VII - Sozinho realiza a peça; VIII - Apresenta elementos estéticos; IX - Possui maior valor econômico que as peças artesanais; $X$ - Expressa emoção do momento da criação; XI - Revela expansão cultural de um povo; XII - Possui um espaço determinado nas galerias, exposições e eventos; XIII - É auxiliada pelo folclore e pela globalização; XVI - É feita por qualquer pessoa, independente do seu nível econômico ou social; e XV - Requer um olhar diferente para ser entendida (MDIC, 2010, p.03-04 grifo nosso).

A partir das definições para artesanato, artes manuais e artes populares descritas, podemos afirmar que as diversas “'maneiras do fazer' constituem as práticas pelas quais usuários se reapropriam do espaço organizado pelas técnicas da produção sociocultural" (CERTEAU, 1998, p. 41). Para desenvolvermos a análise das artes visuais no contexto dos artesanatos é que devemos nos atentar para a definição das artes populares, pois podemos observar sua proximidade com as artes visuais e quiçá aquela seja a precursora desta. Como foi possível de se constatar às inúmeras interpretações, definições expostas, conceitos abordados sobre os termos, para a análise proposta dos 
"artesanatos midiáticos" neste trabalho, optamos pelas conceituações do MDIC por serem mais elaboradas e abrangentes

\subsection{Artes Visuais implícitas nos Artesanato e/ou Manualidades Virtuais e suas relações com as Artes Ensinadas nas Escolas de Ensino Básico}

Segundo Santaella (2016); Kunzler (2010) a arte perdeu suas fronteiras ainda por volta de 1960. A partir de então o ensino de artes, ou melhor, as metodologias de arte que se utilizam das técnicas de reprodução de algum tipo de arte, iriam ser desenvolvidas nas escolas somente após 1970, tendo sua importância para o desenvolvimento das habilidades, sensibilidade e criatividade dos alunos, porém, não enfatizava as artes visuais em toda sua amplitude, mas, segmentos, fragmentos de um ou outro determinado tipo de arte (ênfase na pintura, desenho).

Entretanto, esse ensino de arte e suas novas metodologias ganham ainda mais visibilidade a partir da Lei de Diretrizes e Bases da Educação Nacional (LDB - Lei 9.394/1996). E aumenta a ênfase na medida em que a lei $n$. 13.278/2016 inclui obrigatoriamente as artes visuais e suas várias linguagens nos currículos em todos os níveis da educação básica, pois, a lei altera e dá nova redação ao art. 26, § $6^{\circ}$ da LDB de 1996 definindo as artes visuais e incluindo-a também, em seu $\S 2^{\circ}$ do art. 26 como já estava previsto anteriormente (BRASIL, 1997, p. 25). Dessa maneira, o Ensino de Artes torna-se obrigatório nos diversos níveis da educação básica para dessa maneira proporcionar e promover o desenvolvimento cultural aos alunos.

Bueno (2012, p. 123) afirma que desenvolver a capacidade de lidar com imagens, a manipulação de matérias-primas para a confecção de objetos e/ou produtos artísticos, decorativos, lúdicos, religiosos e, assim compreender as artes visuais em suas diversas formas de expressão, é no presente um dos nossos maiores desafios para os educadores de arte. Afinal, vivemos em uma sociedade plural em vários sentidos, carregada de informações visuais e/ou virtuais, fato implícito em nossas atividades cotidianas, e que em muitas vezes deixamos de dar maior significância nisto, e/ou banalizamos tais fatos. 
Vemos então, neste contexto, que a inserção da prática de manualidades, do artesanato e das artes populares está contemplada assim como as várias metodologias do ensino de artes podem abarcar essas técnicas e práticas desenvolvidas especificamente para estes fazeres também em sala de aula.

Para Ferraz \& Fusari (1993, p. 17) seria nessa abrangência que a arte deve compor os conteúdos de estudos nos cursos de arte e mobilizar as atividades que diversifiquem e ampliem a formação artística e estética daqueles que estudam ou pretendem desenvolver suas habilidades a partir das artes. Ainda, para as autoras, "as vivências emotivas e cognitivas tanto de fazeres quanto de análises do processo artístico nas mobilidades artes visuais [...] devem abordar os componentes - artistas - obras - públicos - modos de comunicação e suas maneiras de interagir na sociedade" (FERRAZ; FUSARI, 1993, p. 17).

Portanto, está patente para autores como Ferraz \& Fusari (1993, p. 49) que as artes visuais são ferramentas importantes no âmbito da educação desde o infantil até o adulto, pois se trata de um estímulo essencial em várias etapas do desenvolvimento humano.

Com esta, ao se trabalhar a criatividade e imaginação do indivíduo, este último consegue adquirir novas habilidades e novas formas de ver o mundo (o conceito estético ou artístico pode ser trabalhado a partir do cotidiano, tanto da natureza quanto da cultura como um todo).

Por consequência "a arte também está presente na sociedade em profissões que são exercidas nos mais diferentes ramos de atividades; o conhecimento em artes é necessário no mundo do trabalho e faz parte do desenvolvimento profissional dos cidadãos" (BRASIL, 1997, p. 19), daí a necessidade desse conhecimento ser difuso em nossa sociedade e de maneira democrática. Portanto, para Kunzler (2010, p. 02) a arte contemporânea assim como as obras artísticas em outros tempos intenta dar sentido a sociedade. Segundo o autor é preciso compreender a arte visual contemporânea como qualquer outra 
arte, o que requer entendê-la e vinculada ao contexto atual, buscando situá-la com questões mais amplas que envolvem o mundo contemporâneo [que] nela se apresenta. Embora os ambientes socioeducativos (salas de aulas físicas ou salas de aulas virtuais) possuam suas especificidades, as artes visuais podem ser difusas, absorvidas, experimentadas por qualquer indivíduo, em qualquer um desses espaços sociais de interação em que participam.

Entretanto, é preciso ter ressalvas quanto ao processo de ensino-aprendizagem, afinal, a arte visual só existe diretamente com aquilo que se visualiza ("ainda que com os toques das mãos" - no imaginário), com o seu fazer, pelo agir e pelo interagir do Ser com o Objeto, portanto, é uma prática relacional e iterativa para tantas outras formas de interação social. E mais, diante das grandes transformações e desafios que vêm ocorrendo em nossa sociedade, como criar novos produtos e serviços sem causar agressão ao meio, ou seja, controlar os impactos ambientais, desenvolver uma gestão ambiental, precisamos pensar, repensar e avançar nas formas de construir e/ou reconstruir os métodos de transmissão do conhecimento, conforme Scarpioni (2001, p. 14), as artes visuais podem e contribuem neste sentido.

Outra questão a ser abordada pelo ensino das artes está na conservação e preservação do meio ambiente, questões tão caras no convívio social na atualidade. O ensino de artes é deveras importante na Educação Ambiental, uma vez que contribui para despertar sensibilidade, motivar a criatividade e promover a inclusão social de cada indivíduo (SCARPIONI, 2001, p. 14).

\subsection{Manualidades na TV e em Rede Midiática}

A partir deste tópico passamos a identificar os muitos programas ${ }^{11}$ televisivos em canais aberto ou de TV a cabo, e ainda, nas redes midiáticas que a partir da primeira década deste novo século, vêm abordando ou inserindo cada vez mais os conteúdos e "elementos básicos de artes visuais" (BUENO, 2012) sob a forma de produtos ditos "artesanais" em sua grade de programação.

11 Como exemplos, citamos: Ateliê na TV, Vida com Arte, Arte Brasil, Armarinho da Arte, entre outros. 
Cabe salientar, que esses espaços se prestam como importante meio de comunicação para a divulgação dos trabalhos manuais de vários profissionais de São Paulo e de todo Brasil. Mas, quais seriam as motivações para tal ocorrência? De acordo com Rodrigues (2016) em seu artigo Arte e Mídia afirma que:

\begin{abstract}
As fronteiras entre os campos da arte e da comunicação são cambiantes: artistas, artesãos, utilizam linguagens, teorias, cenários e ícones da cultura comunicacional. Por outro lado, elementos e experimentações estéticos, antes próprios do domínio artístico, são incorporados aos discursos midiáticos.

$O$ ambiente tecnocultural suscitado a partir da expansão das tecnologias digitais da comunicação no cotidiano instiga, desafia e estimula artistas, teóricos e profissionais, transformando o domínio da criação. As relações entre os meios de comunicação e as artes tomaram corpo a partir do estabelecimento da comunicação massiva, pós-Revolução Industrial (RODRIGUES, 2016, p. 02, grifo nosso).
\end{abstract}

A televisão como já sabido é um recurso visual largamente disseminado e com fortíssimo poder de penetração em todas as classes sociais (BUENO, 2012). Pesquisas do Instituto brasileiro de Geografia e Estatística (IBGE) mostravam na década de 1980, que ela já estava presente em $94 \%$ das residências das regiões metropolitanas.

Cabe ressaltar que os programas que exibiam práticas de confecções de objetos ditos "artesanais" já no final da primeira década deste século foram migrando dos canais de TV aberta para os canais de TV a cabo, especialmente os canais religiosos, além de serem difusos massivamente nas redes midiáticas. Dessa forma, podemos refletir que as novas tecnologias se tornam um meio de criação e de influência das artes (KUNZLER, 2010; BUENO, 2012; GARCIA JÚNIOR, 2014; MACHADO, 2008), uma vez que as artes são reproduzidas de acordo com os meios e as formas de reprodução específica para cada época (RODRIGUES, 2016).

Por isso, segundo Machado (2008, p. 16) o artista digno desse nome vem buscando se apropriar cada vez mais das tecnologias mecânicas, audiovi- 
suais, eletrônicas e digitais numa perspectiva inovadora, fazendo-as trabalhar em benefício de suas ideias estéticas.

\subsection{Arte, Artes Visuais e Artesanatos na Sociedade Capitalista}

A arte, artesanato e capitalismo se imbricam desde tempos remotos, com o surgimento e o "desenvolvimento das cidades e ao aparecimento de atividades urbanas necessárias à vida em coletividade, tais como os padeiros, ferreiros, carpinteiros, marceneiros, tecelões, seleiros, arquitetos, entre outros" (BARROSO NETO, 2001, p.7). E segundo Coli (1995, p.15), os "ofícios, exercidos em ateliês ([...] a partir do século XIV), constituíam um sistema não apenas de produção e de distribuição de objetos, mas também de ensino", e também de uma profissão.

Barroso Neto (2001) afirma que somente a partir do século XVIII teriam surgidas às primeiras corporações de ofícios com a detenção de técnicas, regras e regulamentos rígidos, definindo os limites e atribuições do trabalho artesanal, conseguindo algumas destas entidades notável reconhecimento. Todavia, com o desenvolvimento industrial o artesanato sofreria decadência e até uma marginalização social e econômica, passando então a ser alternativa de consumo (senão a única) para as populações periféricas, mais afastadas dos grandes centros, ou de menor poder aquisitivo, impossibilitadas economicamente de acesso aos bens e serviços produzidos pelas indústrias conforme comenta o autor. No Brasil o artesanato passou a ser uma "atividade alternativa inserida no âmbito dos programas de assistência social, tratado sob uma ótica paternalista, sem considerar suas dimensões econômica e social" (BARROSO NETO, 2001, p.8).

Contudo, como já dito, o artesanato vem ganhando maior espaço na mídia nas últimas duas décadas pela quantidade de artesões espalhados pelo país e pela qualidade, quantidade e diversidade de produtos produzidos, que passam a ser expostos nas mídias, visando alcançar novos consumidores, contribuindo assim para a geração de empregos e desenvolvimento da economia bruta interna do país. 
Segundo "dados do Instituto Brasileiro de Geografia e Estatística (IBGE), existem 310 mil artesãos no Brasil, sendo que o artesanato está presente como atividade econômica em 78,6\% dos municípios brasileiros" (SEBRAE, 2016, p. 01). Outra pesquisa feita pelo Sebrae mostra que $60 \%$ dos artesãos brasileiros têm o artesanato como principal fonte de renda, mas, a comercialização é considerada ainda o principal problema para 29\% deles. Entretanto, em 2013 a atividade do artesanato movimentou mais de $\mathrm{R} \$ 50$ bilhões, envolvendo 8,5 milhões de pessoas nessa atividade (SEBRAE, 2014, p.02), e anuncia que para o próximo Censo já será classificada como ocupação profissional. Assim o artesanato já se configura como uma das principais atividades econômicas em vários municípios brasileiros, contando, cada vez mais, com um mercado que valoriza esse tipo de trabalho, pois, os "artigos de alta qualidade fabricados por brasileiros conquistam o público na Feira de Artesanato Brasil Sebrae Original" (SEBRAE, 2016, p. 01).

O calendário12 brasileiro de exposições e feiras proposto pelo MDIC demonstra o volume de eventos destes segmentos que vem ocorrendo por todo o país (MDIC, 2016). Somente no ano de 2016, ocorreram 16 eventos sobre artesanatos, artes manuais e artes populares como é o caso de alguns exemplos: a MEGA ARTESANAL ${ }^{13}$, FEIARTE ${ }^{14}$, FINNAR ${ }^{15}$, ART MUNDI ${ }^{16}$ entre outras.

O volume de negócios de artesanato cresce a uma taxa de 15\% ao ano, com destaque na exportação para Europa, Japão e Estados Unidos, segundo a Agência Brasileira de Promoção das Exportações e Investimentos (APEXBrasil). Esse mercado internacional está em expansão, permitindo a inúmeros

\footnotetext{
12 Calendário evidentemente não abarca e contempla todas as empresas ou instituições promotoras de eventos, nem todos os eventos nesse segmento que acontecem no País, podendo existir outros com a mesma excelência em realização, qualificação e confiabilidade.

$1311^{\text {a }}$ Feira de Arte e Técnicas de Artesanato

$1438^{\mathrm{a}}$ Feira Internacional de Artesanato

$1510^{\text {a }}$ Feira Internacional de Negócios do Artesanato

$1614^{\mathrm{a}}$ Feira Mundial de Artesanato
} 
artesãos ampliarem significativamente sua produção e valor médio por item produzido. Notavelmente, a mass media ${ }^{17}$ é o ponto convergente entre os grandes produtores de matérias primas, artesãos(ãs), consumidores e o público simpatizante, visto ser um canal de difusão para produtos essencialmente manuais, motivando a prática de fazer objetos ou então consumi-los. Neste processo interacional, expositivo, é que as manualidades podem ser "reconhecidas" como um tipo de arte visual. Como já é possível constatar, a Mega artesanal é considerada a maior feira de trabalhos manuais e decorativos.

Em 2007 a feira possuía apenas 30 estandes, em um processo crescente e de incremento constante. No ano de 2016 a feira já apresentava um número 330 estandes segundo informações divulgadas pelos próprios organizadores do evento - a WR São Paulo, no programa vida com arte. Nota-se então que as artes visuais implicitamente em produtos ditos artesanais respondem por um grande percentual da economia brasileira. Talvez, aqui já identificamos uma motivação para se difundir as práticas ditas artesanais em programas televisivos e nas redes midiáticas.

\subsection{A Análise dos Programas Televisivos e de Redes Midiáticas}

Foi possível fazer registrar os diversos programas televisivos em canais de TV abertos, TV a cabo e nas redes midiáticas que apresentam algum tipo de arte visual na forma de manualidades ou os "ditos artesanatos". Selecionamos 11 programas para análise de conteúdo, identificação do público alvo, perfil de seus apresentadores, convidados, técnicas de arte, metodologias de arte, etc. Pudemos registrar a duração média em cada programa (na TV) é de 35 minutos, sendo mais curtos os programas exibidos nas redes midiáticas, 25 minutos. Veja a tabela 1.

\footnotetext{
17 Meios de comunicação com grande penetração e alcance do público, como: televisão, rádio, jornal, redes sociais, internet, entre outros sistemas específicos que coletam, tratam e divulgam informações direcionadas a grande massa populacional.
} 


\begin{tabular}{|c|c|c|c|c|c|c|}
\hline PROGRAMAS & $\begin{array}{l}\text { PÚBLICO } \\
\text { ALVO }\end{array}$ & $\begin{array}{l}\text { CANAIS } \\
\text { SECULARES E } \\
\text { RELIGIOSOS }\end{array}$ & $\begin{array}{l}\text { PERÍODOS } \\
\text { HORÁRIOS }\end{array}$ & GÊNEROS & APRESENTADORES & SITES/EMAILS/REDES SOCIAIS \\
\hline $\begin{array}{l}\text { Armarinho da } \\
\text { Arte }\end{array}$ & Adulto & $\begin{array}{c}\text { Rede Novo } \\
\text { Tempo Canal } \\
14\end{array}$ & $14: 30 \mathrm{~h}$ & Feminino & Karina do Canto & $\begin{array}{l}\text { www.novotempo.com/ } \\
\text { armarinhodaarte }\end{array}$ \\
\hline Ateliê na TV & Adulto & $\begin{array}{c}\text { Rede Brasil } \\
\text { canais } 175 / \\
\text { Gazeta } 11\end{array}$ & $\begin{array}{l}10: 00 \mathrm{~h} \\
18: 00 \mathrm{~h}\end{array}$ & $\begin{array}{l}\text { Feminino/ } \\
\text { Masculino }\end{array}$ & Dotan Mayo & www.atelienatv.com.br \\
\hline Arte Brasil & Adulto & $\begin{array}{l}\text { Canal Rural } \\
\text { Canal } 159\end{array}$ & $14: 00 \mathrm{~h}$ & Feminino & Rita Maria & Facebook.com/artebrasil \\
\hline $\begin{array}{l}\text { Vida com } \\
\text { Arte }\end{array}$ & Adulto & $\begin{array}{c}\text { Rede } \\
\text { Aparecida } \\
\text { Canal } 178\end{array}$ & $\begin{array}{l}04: 00 \mathrm{~h} \\
07: 00 \mathrm{~h} \\
14: 00 \mathrm{~h}\end{array}$ & $\begin{array}{l}\text { Feminino/ } \\
\text { Masculino }\end{array}$ & $\begin{array}{l}\text { Claudia } \\
\text { Pacheco }\end{array}$ & www.a12.com.br \\
\hline $\begin{array}{l}\text { Hora de } \\
\text { Brincar }\end{array}$ & Infantil & $\begin{array}{l}\text { Rede Vida } \\
\text { Canal } 162\end{array}$ & $8: 30 \mathrm{~h}$ & $\begin{array}{l}\text { Feminino/ } \\
\text { Masculino }\end{array}$ & Danny Pink & www.redevida.com.br \\
\hline Vida Melhor & Adulto & $\begin{array}{l}\text { Rede Vida } \\
\text { Canal } 162\end{array}$ & $14: 00 \mathrm{~h}$ & $\begin{array}{l}\text { Feminino/ } \\
\text { Masculino }\end{array}$ & Claudia Tenório & www.redevida.com.br \\
\hline Tia Cecéu & Infantil & $\begin{array}{c}\text { Rede Novo } \\
\text { Tempo Canal } \\
14\end{array}$ & $9: 00 \mathrm{~h}$ & $\begin{array}{l}\text { Feminino/ } \\
\text { Masculino }\end{array}$ & Mariceu Iglesias & $\begin{array}{c}\text { tiaceceu@novotempo.co } \\
\text { m/tiaceceu }\end{array}$ \\
\hline Arte que Faz & Adulto & $\begin{array}{l}\text { Play TV } \\
\text { Canal } 181\end{array}$ & $\begin{array}{c}10: 00 \\
3^{a} \text { e } 5^{a} \\
\text { feiras }\end{array}$ & Feminino & Lili Giusti & Facebook.com/artequefaz \\
\hline $\begin{array}{c}\text { Nosso } \\
\text { Programa }\end{array}$ & Adulto & $\begin{array}{l}\text { Rit TV } \\
\text { Canal }\end{array}$ & $14: 00 \mathrm{~h}$ & Feminino & $\begin{array}{l}\text { Jacqueline } \\
\text { Stefano }\end{array}$ & $\begin{array}{c}\text { Facebook.com/ } \\
\text { jacqquelinestefano }\end{array}$ \\
\hline Kombina & Adulto & $\begin{array}{c}\text { Rede } 12 \\
\text { Aparecida } \\
\text { Canal } 178\end{array}$ & $\begin{array}{c}10: 00 \mathrm{~h} \\
- \\
12: 00 \mathrm{~h}\end{array}$ & $\begin{array}{l}\text { Feminino/ } \\
\text { Masculino }\end{array}$ & Bete Ribeiro & Facebook.com/kombina \\
\hline $\begin{array}{l}\text { Vida Plena } \\
\text { Legião da } \\
\text { Boa Vontade }\end{array}$ & Adulto & Canal 21 & $11: 00$ & $\begin{array}{l}\text { Feminino/ } \\
\text { Masculino }\end{array}$ & $\begin{array}{l}\text { Letícya } \\
\text { Elizabeth }\end{array}$ & $\begin{array}{l}\text { www.youtube.com/ } \\
\text { boavontadetv }\end{array}$ \\
\hline
\end{tabular}

Tabela 1. Registro de Programas Televisivos e Programas em Redes Midiáticas Fonte: elaborado pela autora, 2016.

É possível notar através da tabela, quão próximas são as relações das instituições religiosas com as manualidades e com a mídia. Consecutivamente, são compreensíveis algumas motivações para se apresentar 0 artesanato midiático em sua grade de programação, uma vez que é preciso relembrar que a arte sacra é também simbólica, e como tal, também é a própria mídia. Os ritos religiosos de uma maneira geral estão cheios de simbolismos intrínsecos às imagens, esculturas, pinturas, arquiteturas, etc. Nestes estão também inseridos a arte visual. 
Através de uma busca simples e rápida na internet com a seguinte pergunta "cursos de artesanato ofertados pelas igrejas" podemos observar os mais diversificados segmentos ${ }^{18}$ religiosos que ofertam tais atividades sob a forma de oficinas, cursos, projetos, por consequência, possuindo inúmeras finalidades: inserção e penetração do proselitismo religioso, terapia de grupo, convivência e reinserção social, dinâmica e mudanças comportamentais, etc.

De acordo com Scarpioni (2016, p.42) as religiões pentecostais [entre outras] também moldam comportamentos sociais, forjam dinâmicas culturais a partir de suas doutrinas e dogmas, interagirem com as políticas públicas, bem como, influenciam - ainda que indiretamente - as economias locais, fazendo isto por meio da confecção de bens e produtos simbólicos. Haja vista, que "bens simbólicos passam a ser transformados em bens materiais, ou seja, um bem considerado sagrado que sai dos 'limites sagrados' indo ocupar e ser difuso nos 'espaços de bens profanos'" (SCARPIONI, 2016, p. 44) para serem consumidos pelo público em geral.

Também a partir dos conteúdos dos programas e com o auxílio de outras pesquisas realizadas feitas pelo Sebrae por amostragem, pudemos traçar em paralelo, ainda que indiretamente, do perfil do público alvo que estes programas atingem. A pesquisa realizada pelo Sebrae junto aos artesões espalhados pelo Brasil, mostra que $77 \%$ desenvolvem seus trabalhos em casa e $23 \%$ em outros lugares (SEBRAE, 2013a, p.14) daí uma das motivações ou porquês para a difusão dos programas que abordam esse tipo de atividade na televisão e em outras mídias.

A pesquisa traz que os trabalhos manuais são feitos majoritariamente por mulheres casadas (60\%), com idade acima dos 50 anos (63\%) variando o grau de escolaridade entre fundamental e médio, motivadas pelo desejo, necessidade de ajudar no orçamento familiar ou pelas vendas diretas, por não terem lojas.

18 Católicos, Adventistas do Sétimo Dia, Presbiteriana Independente, Batista, Metodistas, entre outras 
Muitas trabalham com esse tipo de atividade por um período médio de 7 horas diárias (SEBRAE, 2013a, p. 18), sendo assim "donas de seu próprio negócio". Outra pesquisa realizada pelo Centro Cape, em 2009 detalha o perfil do público consumidor de artesanato no Brasil (SEBRAE, 2014, p.02). O perfil dos que desenvolvem alguma atividade manual seria "predominantemente feminino (74\% dos entrevistados), a idade média está acima dos 40 anos, sendo que $41 \%$ têm o ensino médio e $39 \%$ superior, somente $19 \%$ tem até a $8^{a}$ Série (atual $9^{\circ}$ ano).

Os principais itens de consumo são os utilitários seguidos dos itens de decoração (SEBRAE, 2014, p.02). Nota-se que os ensinamentos religiosos, os programas televisivos e seus patrocinadores buscam atingir o alvo que são as mulheres em geral, que não trabalham fora de casa e que necessitam ou desejam ter complementação de renda familiar. Ainda em outra pesquisa feita também pelo Sebrae para traçar o perfil dos comerciantes que trabalham com esse tipo de produto manual foi possível observar que: $35 \%$ comercializam peças decorativas, $10 \%$ de cama e mesa, $9 \%$ bijuterias, $7 \%$ tecelagem, $5 \%$ bolsas (SEBRAE, 2013b, p. 14).

Registramos que todos estes produtos estão presentes nos conteúdos dos programas televisivos aqui pesquisados, sendo produzidos, ou advindos basicamente de manualidades produzidas por mulheres. Podemos observar que as pessoas e as instituições que lidam com esses programas e os projetos de apoio às práticas manuais veiculam seus produtos diversificados sempre sob a mesma nomenclatura (artesanatos), e consequentemente sob as mesmas estratégias, entretanto, não atentando para os cuidados na diferenciação de produtos tão dispares quanto podem ser as peças exclusivas de arte popular ou pequenos souvenires semi-industrializados. Para Barroso Neto (2001, p. 24 ) isto é um equívoco que pode acarretar uma série de consequências dentre elas: uma perda da visão da multiplicidade cultural e étnica do artesanato, portanto, produtos de diferentes origens são transformados em "curiosidades". 


\section{CONSIDERAÇÕES FINAIS}

Diante das análises dos conteúdos dos programas televisivos e em redes midiáticas, concluímos que tais programas não difundem de fato o artesanato e sim manualidades, nem mesmo, abordam as artes populares seguindo seus conceitos. Todavia, corriqueiramente utilizam o termo arte, artesanato no título de seus quadros e aberturas de seus programas sem nenhum tratamento conceitual. Logo os "artesanatos midiáticos" não se fixam em definições legais e nem mesmo em tradições regionais, culturais e nem tão pouco históricas.

Não se pode afirmar categoricamente que as artes visuais são apresentadas, abordadas, nestes programas, mas, que elementos básicos de artes visuais estão implícitos nas manualidades, pois é possível parcialmente visualizar elementos essenciais das artes visuais nos trabalhos exibidos, ensinados pelos ditos "professores de artes" e/ou "artesãos(ãs)". Outra questão seria quanto às metodologias de ensino dessas práticas, pois estas estão muito aquém das metodologias de artes praticadas em estabelecimentos de ensino, especialmente no que tange ao ensino de artes visuais como propõe à legislação pertinente as artes, pois, as técnicas se resumem a uma ou outra linguagem de arte, com a maior ênfase para as pinturas e colagens em tecidos, excluindo outras linguagens de arte.

Outro fator que compromete a questão das artes visuais nesses programas, seria a existência de um marketing com forte apelo comercial de produtos e de matérias-primas para a confecção de objetos, fato que descaracteriza essencialmente a arte, o artesanato, a essencialidade da artesã(ão), isto porque, o telespectador(a) é motivado(a), impelido(a) a se tornar um consumidor(a) ativo de materiais (revistas, CDs, etc.). Afinal, as artes visuais têm funções estéticas, práticas e simbólicas que também estão presentes nos artesanatos, mas, estes últimos precisam ser preservados, fato que não ocorre nos artesanatos midiáticos. Assim, o trabalho prestou-se à reflexão e compreensão 
das várias formas de artes visuais nos diversos nichos físicos ou virtuais, bem como sua penetração em outras áreas do conhecimento.

\section{REFERÊNCIAS}

AMARAL, V. L. A Inteligência (2007). Disponível em: <http://www.ead.uepb.edu.br/ arquivos/cursos/Geografia_PAR_UAB/Fasciculos\%20-20Material/Psicologia_educacao/Psi_Ed_A02_J_GR_20112007.pdf> Acesso em: 10 Nov. 2016.

ANDRADE, M. de. O Artista e o Artesão (1938). Disponível em: <https://www.eba.ufmg.br/alunos/kurtnavigator/arteartesanato/filos-03-artesao.html.> Acesso em: 14 out. 2016.

BARROS, A. Arte: Um tecido de Luz. In: BARROS, A.; SANTAELLA, L. (Orgs.) Mídias e Artes - Os desafios da arte no início do Século XXI. São Paulo: Unimarco Editora, 2002. p. 33-57.

BARROSO NETO, E. O que é Artesanato - Curso Artesanato - módulo 1 (2001). Disponível em: <http://www.fbes.org.br/index.php?option=com_docman\&task=doc_ download\&Itemid=99999999\&gid=601> Acesso em: 03 jun. 2016.

BENJAMIM, W. A obra de arte na era da sua reprodutibilidade técnica. In: Magia e Técnica, Arte e Política: Ensaios sobre literatura e história da cultura. [trad. Sérgio Paulo Rouanet, pref. Jeanne Marie Gagnebin]. $3^{\mathrm{a}}$ ed. São Paulo: Brasiliense, 1987. V.1. p. 165-196.

BRASIL. Parâmetros Curriculares Nacionais: Arte. Brasília: Secretaria de Educação Fundamental - MEC/SEF, 1997.

Lei $\mathbf{n} .13 .180$, promulgada em 22 de outubro de 2015. Dispõe sobre a profissão de artesão e dá outras providências. Disponível em: <https://www.planalto. gov.br/ccivil_03/_ato2015-2018/2015/lei/l13180.htm> Acesso em: 13 dez. 2016.

Lei $\mathbf{n . 1 3 . 2 7 8}$, promulgada em 03 de maio de 2016. Altera o $\S$ $6^{\circ}$ do art. 26 da Lei no 9.394 , de 20 de dezembro de 1996 , que fixa as diretrizes e bases da educação nacional, referente ao ensino da arte. Altera o $\S 6^{\circ}$ do art. 26 da Lei no 9.394, de 20 de dezembro de 1996, que fixa as diretrizes e bases da educação nacional, referente ao ensino da arte. Disponível em: <https:// www.planalto.gov.br/ ccivil_03/_ato2015-2018/2016/lei//13278.htm> Acesso em 18 dez. 2016.

BUENO, L. E. B. Linguagem das Artes Visuais. 1 ed. Curitiba: Intersaberes, 2012.

CERTEAU, M. A Invenção do Cotidiano: Artes de Fazer. $3^{\text {a }}$ ed. [trad. Efrhaim Ferreira Alves] Petrópolis-RJ: 1998. p. 39.

COLI, J. O que é Arte. 15 ed. São Paulo: Brasiliense, 1995. (Coleção Primeiros Passos). 
CONDO, T.; MARTINS, C. A.; SCARPIONI, M. Recursos Audiovisuais Aplicados na Formação de Professores de Ciências. In: 50a Reunião Anual SPBC Ciência, Educação e Investimento, 1998, Anais..., Natal-RN, UFRN/SBPC, 1998, p. 648.

ENGELMANN, A. A. Filosofia de Arte. Curitiba: Intersaberes, 2012. p. 38-65.

FERRAZ, M. H. C. de T.; FUSARI, M. F. de R. Metodologia do Ensino de Arte. São Paulo: Cortez, 1993. (Coleção Magistério $2^{\circ} \mathrm{Grau}$ - série formação do Professor).

GARCIA JÚNIOR, J. A. Apostila de Artes Visuais. Disponível em: <www.imagetica.net/blog> Acesso em: 27 dez. 2016.

GOLEMAN, D. Inteligência Emocional: A teoria revolucionária que define o que é ser inteligente (2011). Disponível em: <https://lelivros.top/book/baixar-livro-inteligen ciaemocional-daniel-goleman-em-pdf-epub-e-mobi-ou-ler-online/> Acesso em: $10 \mathrm{dez}$. 2016.

KUNZLER, N. A. A arte visual no mundo contemporâneo (2010). Disponível em: <https://periodicos.ufsm.br/revislav/article/view/2133/1295> Acesso em: 10 out. 2016.

LAKOMY, A. M. Teorias Cognitivas da Aprendizagem. Curitiba: Intersaberes, 2012. p. 55-62.

LIMA, R. G. Artesanato e arte popular: duas faces de uma mesma moeda? (2011) Disponível em: <http://www.cnfcp.gov.br/pdf/Artesanato/Artesanato_e_Arte_Pop/

CNFCP_Artesanato_Arte_Popular_Gomes_Lima.pdf.>Acesso em: 02 out. 2016.

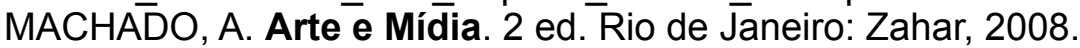

[MDIC] MINISTÉRIO DO DESENVOLVIMENTO, INDÚSTRIA E COMÉRCIO EXTERIOR. Portaria n. 29, de 5 de Outubro de 2010. Preconiza a base conceitual do artesanato brasileiro, na forma do Anexo, para padronizar e estabelecer os parâmetros de atuação do Programa do Artesanato Brasileiro - PAB em todo o território nacional. Disponível em: <http://www.smpe.gov.br/documentos/portaria-no-29-glossario_01.pdf> Acesso em: 01 nov. 2016.

Calendário Brasileiro de Exposições e Feiras 2016. Disponível em: <http://www.investexportbrasil.gov.br/sites/default/files/publicacoes/ publicacoes/ CalendarioFeiras2016_P.pdf> Acesso em: 05 dez. 2016.

RODRIGUES, C. G. Arte e Mídia. Disponível em: <http://www.sfbbrasil.org/ midia_o_que_e.htm> Acesso em: 20 set. 2016.

SANTAELLA, L. A arte contemporânea e seus enigmas. Disponível em: <https:// art.medialab.ufg.br/up/779/o/lucia_santaella.pdf> Acesso em: 03 jan. 2019.

SCARPIONI, M. Experimentoteca: Uma Estratégia para a Formação de Professores de Química - Estudo de sua Aplicabilidade e Sistematização de Materiais Produzidos. 2001. 78 p. Monografia (Bacharelado em Química). Centro Universitário Fundação Santo André, Santo André - SP, 2001. 
Artigos religiosos nos pentecostalismos: Estudo das relações dos bens simbólicos na geração de economia local em Rio Grande da Serra, periferia urbana no

Grande ABC. Luminária. Curitiba, v.18, p.41 - 58, 2016.

[SEBRAE] SERVIÇO BRASILEIRO APOIO A MICRO E PEQUENA EMPRESA. Termo de Referência - Atuação do Sistema SEBRAE no Artesanato. Brasília: SEBRAE, 2010.

Pesquisa - O Artesão Brasileiro (2013a). Disponível em: <http://www.bibliotecas.sebrae.com.br/chronus/ARQUIVOS_CHRONUS/bds/bds.nsf/ e91d1404887c8d41edfcb441d54bf6de/\$File/5131.pdf> Acesso em: 13 nov. 2016.

Pesquisa com Comerciantes de Artesanato (2013b). Disponível em: <http://www.bibliotecas.sebrae.com.br/chronus/ARQUIVOS_CHRO NUS/bds/bds.nsf/5fa14f75994c971bb24c07f89b93df84/\$File/5141.pdf> Acesso em: 13 nov. 2016.

Como montar uma loja de artesanatos (2014). Disponível em: <www.sebrae.com.br> Acesso em: 25 out. 2016

Artesanato de todo o país atrai quase 10 mil visitantes em apenas dois dias (2016). Disponível em: <http://feiradeartesanato.sebraesp. com.br/ noticia/artesanato-de-todo-o-pais-atrai-quase-10-mil-visitantes-em-apenas-do is-dias> Acesso em: 25 out. 2016.

SMOLE, K.C.S. Múltiplas Inteligências na Prática Escolar. Brasília: Ministério da Educação, Secretaria de Educação a Distância, 1999. (Cadernos da TV Escola).

[SUTACO] SUPERINTENDENNCIA DO TRABALHO ARTESANAL NAS COMUNIDADES. Dicas - $O$ que é Artesanato. Disponível em: <www.sutaco.sp. gov.br/> Acesso em: 27 ago. 2016.

Superintendência do Trabalho Artesanal nas Comunidades. Disponível em: <https://pt.wikipedia.org/wiki/Superintend\%C3\%A Ancia_do_Trabalho_Artesanal_nas_Comunidades> Acesso em: 27 mai. 2018.

ZAGONEL, B. A Arte na Educação Escolar. Curitiba: Intersaberes, 2012.

Recebido em 27 de maio de 2018 Aprovado em 29 de junho de 2019 